\section{Photodegradation of FeDTPA in Nutrient Solutions. I. Effects of Irradiance, Wavelength, and Temperature}

\author{
Joseph P. Albano ${ }^{1}$ \\ U.S. Department of Agriculture, Agricultural Research Service, 2001 S. Rock \\ Road, Fort Pierce, FL 34945 \\ William B. Miller ${ }^{2}$ \\ Department of Horticulture, Box 340375, Clemson University, Clemson, \\ SC 29634-0375
}

Additional index words. plant nutrition, FeDTPA, FeEDTA, Fe-chelate, photochemistry

\begin{abstract}
Irradiation of FeDTPA-containing nutrient solutions by a fluorescent plus incandescent light source resulted in the loss of both Fe-chelate and soluble $\mathrm{Fe}$, the formation of a precipitate that was composed mostly of $\mathrm{Fe}$, and a rise in $\mathrm{pH}$. The rate of Fe-chelate photodegradation in solution increased with irradiance intensity and with solution temperature under irradiation, but irradiance had the greater effect. Fe-chelates absorb in the blue and UV regions of the spectrum. Removal of these wavelengths with a spectral filter eliminated photodegradation. Chemical name used: ferric diethylenetriaminepentaacetic acid (FeDTPA).
\end{abstract}

Maintaining a sufficient level of micronutrients, particularly $\mathrm{Fe}$, in a soluble, readily available form within a $\mathrm{pH}$ range suitable for the production of most plants is difficult without the use of chelates. A metal-chelate complex results when the chelating agent forms multiple bonds with the metal ion. These bonds occur in a ring structure around the metal ion, yielding a configuration in which the ion is nearly surrounded by the chelating agent, maintaining the metal in a soluble form in chemical environments where it would otherwise precipitate (Kolthoffet al., 1969). Chelating agents like diethylenetriaminepentaacetic acid (DTPA), ethylenediaminetetraacetic acid (EDTA), and ethylenediaminedi-o-hydroxy-

Received for publication 15 Mar. 2000. Accepted for publication 19 July 2000. We thank Dennis R. Decoteau, Thomas M. McInnis, W. Vance Baird, and William C. Bridges, Jr. for consultation in this research. We thank Beth Hardin for technical assistance. This research was supported in part by the Clemson Univ. Ornamental Horticulture Competitive Grants Program and The Fred C. Gloeckner Foundation. Use of trade names does not imply endorsement of the products named nor criticism of similar ones not named. The cost of publishing this paper was defrayed in part by the payment of page charges. Under postal regulations, this paper therefore must be hereby marked advertisement solely to indicate this fact.

${ }^{1}$ Research Horticulturist. To whom requests for reprints should be addressed. E-mail address: jalbano@ushrl.ars.usda.gov. A portion of this research was conducted in partial fulfillment of the requirements for the $\mathrm{PhD}$ degree, Plant Physiology, at Clemson Univ.

${ }^{2}$ Professor. Current address: Dept. of Floriculture and Ornamental Horticulture, Cornell Univ., Ithaca, NY 14853. phenylacetic acid (EDDHA) have a high affinity for $\mathrm{Fe}$ and will form a stable complex with the metal across a $\mathrm{pH}$ range from 4.0 to $7.0,4.0$ to 6.3 , and 4.0 to 9.0 , respectively (Norvell, 1971).

The vulnerability of FeEDTA in solution to photodegradation was first reported in the mid1950s when it was found that ultraviolet (UV) and blue radiation could destroy the chelate complex, yielding ferrous $\mathrm{Fe}\left(\mathrm{Fe}^{2+}\right)$, glyoxylic acid, formaldehyde, $\mathrm{CO}_{2}$, and an amine residue (Frisell et al., 1959; Hamaker, 1956). In the early 1990s, Hangarter and Stasinopoulos (1991) showed that FeEDTA incorporated into tissueculture agar was vulnerable to photodegradation. The Fe-chelate FeEDDHA is also vulnerable to photodegradation (Wallace et al., 1967). To our knowledge, there have been no studies on the vulnerability of FeDTPA to photodegradation or how this photochemical event would alter a nutrient solution used in a hydroponic system. Therefore, the objectives of this study were to determine: 1) if FeDTPA photodegrades in nutrient solutions prepared in the laboratory; 2) the effects of light quality, irradiance, and temperature on this photochemical event; and 3) how FeDTPA photodegradation alters the nutrient solution. For comparison, FeEDTA, a Fe-chelate known to be vulnerable to photodegradation, was also included in these studies.

\section{Materials and Methods}

Photodegradation of FeDTPA in solution. Solutions of FeDTPA or FeEDTA (89.5 $\left.\mu \mathrm{mol} \cdot \mathrm{L}^{-1} \mathrm{Fe}\right)$ were contained $(400 \mathrm{~mL})$ in translucent 500-mL low-density polyethylene (LDPE) bottles (Nalgene Co., N.Y.). Iron chelate solutions were irradiated for $4 \mathrm{~d}$ with 500 $\mu \mathrm{mol} \cdot \mathrm{m}^{-2} \cdot \mathrm{s}^{-1}$ of light (330-800 nm), measured at the external container surface. Containers were placed on their sides for irradiation and control containers were covered with aluminum foil (nonirradiated solutions). Irradiance was varied by adjusting lamp-bank distance from the containers. The radiation source was fluorescent plus incandescent lamps. The study was conducted in a controlled-environment growth chamber and solution temperature was maintained at $20^{\circ} \mathrm{C}$ by adjusting air temperature. At the end of the study, solutions were centrifuged at $6000 g_{\mathrm{n}}$ for $1 \mathrm{~h}$ in a Sorval SA-600 fixed-angle rotor (DuPont Instruments, Wilmington, Del.) at $22^{\circ} \mathrm{C}$. The supernatant $(50 \mathrm{~mL})$ was placed in a $100 \times 15-\mathrm{mm}$ diameter polystyrene petri dish (Becton Dickinson and Co., Lincoln Park, N.J.) in a controlled-environment growth chamber providing $500 \mu \mathrm{mol} \cdot \mathrm{m}^{-2} \cdot \mathrm{s}^{-1}$ of light $(330-800 \mathrm{~nm})$ measured at the surface of the dish from a fluorescent plus incandescent light source. The petri dish was placed on a quantum sensor and the spectral characteristics of the supernatant were determined by spectroradiometric analysis of the radiant flux through the solution (light path $=1 \mathrm{~cm}$ ) with a spectroradiometer (model LI-1800; LI-COR, Lincoln, Nebr.).

Photodegradation of FeDTPA in nutrient solution. A base nutrient solution, previously described (Albano and Miller, 1996), containing FeDTPA or FeEDTA was prepared as a $5 \times$ concentrate stock based on a $14.28 \mathrm{mmol} \cdot \mathrm{L}^{-1}$ $\mathrm{N}\left(17.9 \mu \mathrm{mol} \cdot \mathrm{L}^{-1} \mathrm{Fe}\right) 1 \times$ concentration. Nutrient solutions $(400 \mathrm{~mL})$ were contained in translucent $500 \mathrm{~mL}$ LDPE bottles and irradiated for $48 \mathrm{~h}$ with $500 \mu \mathrm{mol} \cdot \mathrm{m}^{-2} \cdot \mathrm{s}^{-1}$ of light (330-800 nm) as described above except that the radiation source was high intensity discharge (HID), metal halide lamps. Irradiance was varied by adjusting the distance from the lamp to the container surface. Four replications of each treatment were made in a completely randomized design. The $\mathrm{pH}$ of the nutrient solution was between 4.8-4.9 and was not modified. At 6-h intervals, a $20-\mathrm{mL}$ aliquot was drawn from each container after agitation and $\mathrm{pH}$ was determined. Samples were then centrifuged at $6000 g_{\mathrm{n}}$ for $20 \mathrm{~min}$ in a Sorval SA-600 angle-head rotor at $22{ }^{\circ} \mathrm{C}$. The supernatant was analyzed for $\mathrm{Fe}, \mathrm{Mn}, \mathrm{Zn}$, $\mathrm{Cu}, \mathrm{K}, \mathrm{Ca}$, and $\mathrm{Mg}$ by atomic absorption spectrophotometry (AA), and colorimetrically for P according to Jackson (1958). FeEDTA and FeDTPA were measured spectrophotometrically (model DU-64; Beckman Instruments, Fullerton, Calif.) at $258 \mathrm{~nm}$ and 260 $\mathrm{nm}$, respectively, as described by HillCottingham (1957). Absorbance was linear from 1.79 to $89.5 \mu \mathrm{mol} \cdot \mathrm{L}^{-1}$ for both FeEDTA and FeDTPA standards (data not shown). Iron determined by AA includes all forms of soluble $\mathrm{Fe}$ (i.e., Fe-chelates and Fe-salts); FeDTPA and FeEDTA determined spectophotometrically is specific to those forms of Fe only.

Analysis of precipitate. A base nutrient solution, previously described (Albano and Miller, 1996) containing FeDTPA or FeEDTA was prepared as a $4 \times$ concentrate stock based on a $14.28 \mathrm{mmol} \cdot \mathrm{L}^{-1} \mathrm{~N}\left(17.9 \mu \mathrm{mol} \cdot \mathrm{L}^{-1} \mathrm{Fe}\right) 1 \times$ concentration. Nutrient solutions $(8 \mathrm{~L})$ were 
contained in translucent 10-L LDPE carboys (Nalgene Co.). Nutrient solutions were irradiated for $9 \mathrm{~d}$ with $500 \mu \mathrm{mol} \cdot \mathrm{m}^{-2} \cdot \mathrm{s}^{-1}$ of light $(330-800 \mathrm{~nm})$ as described above. The radiation source was HID, metal halide lamps. Solution temperature was not controlled and was $\approx 30^{\circ} \mathrm{C}$. The precipitate that formed during irradiation was analyzed by centrifuging $2.4 \mathrm{~L}$ of the solution at $12,000 \mathrm{~g}_{\mathrm{n}}$ for $1 \mathrm{~h}$ in a Sorval GS-3 rotor at $22{ }^{\circ} \mathrm{C}$. The pellet was resuspended in $\approx 30 \mathrm{~mL}$ of distilled-deionized water, vortexed, and centrifuged at $6000 g_{\mathrm{n}}$ for $1 \mathrm{~h}$. This washing step was repeated three times, then the pellet was dissolved in $24 \mathrm{~mL}$ of $1 \mathrm{~N} \mathrm{HCl}$. Upon centrifugation $\left(6000 g_{\mathrm{n}}\right)$, a clear, light yellow supernatant was obtained. The supernatant and pellet-derived solutions were analyzed for $\mathrm{Fe}, \mathrm{Mn}, \mathrm{Zn}, \mathrm{Cu}, \mathrm{K}, \mathrm{Ca}$, and $\mathrm{Mg}$ by AA, and colorimetrically for $\mathrm{P}$ according to Jackson (1958).

Kinetic analysis of $\mathrm{Fe}$-chelate photodegradation. A base nutrient solution previously described (Albano and Miller, 1996) was prepared as a $5 \times$ or $10 \times$ concentrate stock based on a $14.28 \mathrm{mmol} \cdot \mathrm{L}^{-1} \mathrm{~N} 1 \times$ concentration containing either FeDTPA or FeEDTA. Solutions $(400 \mathrm{~mL}$ of $5 \times$ or $900 \mathrm{~mL}$ of $10 \times)$ were contained in 500- or 1000-mL LDPE bottles, which were placed on their sides and irradiated for $10 \mathrm{~d}$ with $250 \mu \mathrm{mol} \cdot \mathrm{m}^{-2} \cdot \mathrm{s}^{-1}$ or 500 $\mu \mathrm{mol} \cdot \mathrm{m}^{-2} \cdot \mathrm{s}^{-1}$ of light $(330-800 \mathrm{~nm})$, measured at the external container surface. Control containers were covered with aluminum foil. Irradiance was varied by adjusting the distance from the lamp (fluorescent plus incandescent) bank to the container surface. Solution temperature was $20^{\circ} \mathrm{C}$ or $40{ }^{\circ} \mathrm{C}$ and was maintained by adjusting air temperature. Controlledenvironment growth chambers were programmed to provide the combinations of solution temperature and irradiance indicated in Table 2. Three replications were used per treatment. At 24-h intervals, the containers were agitated and a $20-\mathrm{mL}$ aliquot was drawn from each container and centrifuged at $6000 g_{n}$ for $20 \mathrm{~min}$ in a Sorval SA-600 fixed-angle rotor at $22{ }^{\circ} \mathrm{C}$. The supernatant was analyzed for $\mathrm{Fe}, \mathrm{Mn}, \mathrm{Zn}, \mathrm{Cu}, \mathrm{K}, \mathrm{Ca}$, and $\mathrm{Mg}$ by $\mathrm{AA}$, and colorimetrically for $\mathrm{P}$ according to Jackson (1958). Reaction order of FeDTPA and FeEDTA photodegradation was determined by plotting soluble $\mathrm{Fe}\left(\mu \mathrm{mol} \cdot \mathrm{L}^{-1}\right)$ (zero-order), the $\log$ of soluble Fe (first-order), and 1/soluble $\mathrm{Fe}$ (second order) vs. time, with the correct reaction order yielding a straight line. Photodegradation of FeDTPA and FeEDTA, based on the disappearance of soluble Fe over time, was determined to be a first-order reaction. The rate constant $(k)$ was calculated from the raw data by linear regression analysis of the logarithm of soluble $\mathrm{Fe}$ vs. time (i.e., disappearance of substrate).

Light source spectra. The spectral distribution for the fluorescent plus incandescent and HID light sources and the transmission spectra for the fluorescent plus incandescent light source under spectral filter Acrylic yellow2208 are presented in Fig 1. Spectra (330-800 $\mathrm{nm}$ ) were measured at $10-\mathrm{nm}$ intervals with a LI-1800 spectroradiometer (LI-COR) with a quantum sensor.
Statistics. Data were analyzed by analysis of variance (ANOVA) to determine the effects of treatments. Calculations were performed with the general linear model (GLM) procedure of SAS (SAS Institute, Cary, N.C.). Means were separated and planned comparisons were made using LSD or pairwise $t$ tests.

\section{Results and Discussion}

Fe-chelate photodegradation in solution. Freshly prepared (nonirradiated) solutions of FeDTPA and FeEDTA absorbed strongly in the UV and blue regions of the spectrum (Fig. 2). Upon irradiating Fe-chelate solutions for $4 \mathrm{~d}$ with $500 \mu \mathrm{mol} \cdot \mathrm{m}^{-2} \cdot \mathrm{s}^{-1}(330-800 \mathrm{~nm})$ from a fluorescent plus incandescent light source, soluble Fe decreased (data not shown) in conjunction with the formation of a precipi- tate and a decrease of absorbance in the blue and UV regions of the spectrum, indicating the loss of the Fe-chelate complex (Fig. 2). In the irradiated nutrient solutions, the loss of FeDTPA and FeEDTA (Fig. 3A) paralleled the loss of soluble Fe (Fig. 3B), confirming that: 1) FeDTPA photodegrades in lab-prepared nutrient solutions; and 2) the destruction of the chelate results in Fe precipitation in such solutions. The solutions of FeDTPA that were irradiated under a spectral filter with a wavelength cutoff below $454 \mathrm{~nm}$ (Acrylic yellow-2208) neither photodegraded, nor lost soluble $\mathrm{Fe}$ or formed of a precipitate (Fig. 4A). This indicates that the wave-bands of absorbance $(<454 \mathrm{~nm})$ are responsible for the photodegradation of the chelate and subsequent loss of soluble Fe from FeDTPA in solution. These results are similar to those reported for FeEDTA incorporated into

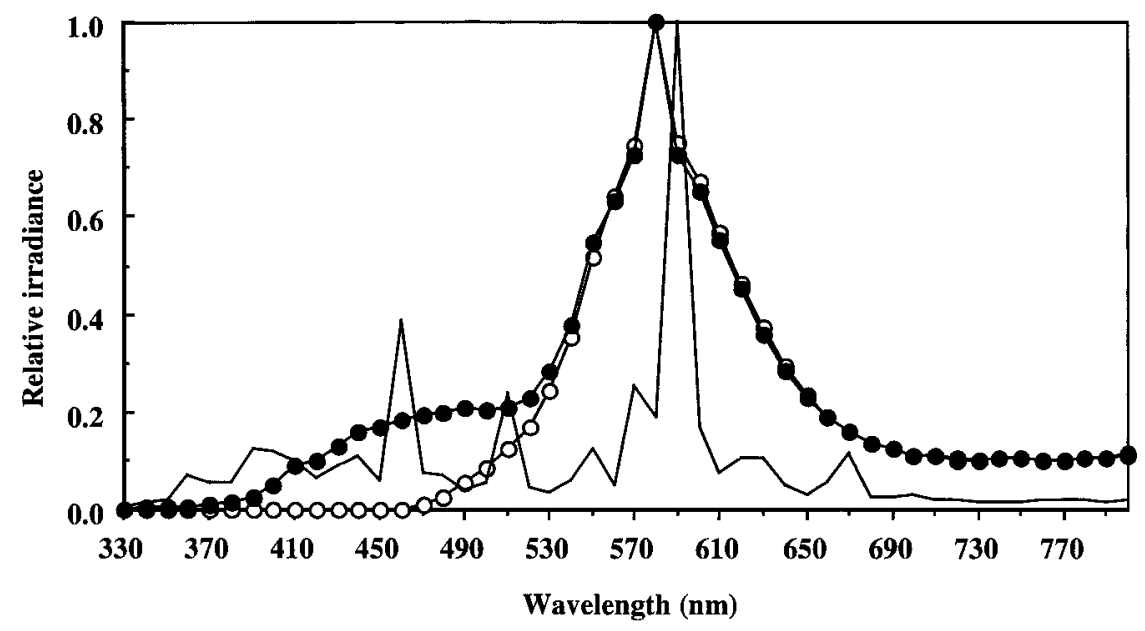

Fig. 1. Spectral photon distribution of a fluorescent plus incandescent light source providing 250 $\mu \mathrm{mol} \cdot \mathrm{m}^{-2} \cdot \mathrm{s}^{-1}$ or $500 \mu \mathrm{mol} \cdot \mathrm{m}^{-2} \cdot \mathrm{s}^{-1}(\Theta)$. Transmission spectra of same light source under spectral filter Acrylic yellow-2208 (wavelength cutoff below $454 \mathrm{~nm}$ ) $(\bigcirc)$. Spectral energy distribution of a HID light source providing $500 \mu \mathrm{mol} \cdot \mathrm{m}^{-2} \cdot \mathrm{s}^{-1}(-)$. Spectra are relative to $580 \mathrm{~nm}$ (irradiance $=1$ ) for the fluorescent and incandescent light source, and $590 \mathrm{~nm}$ (irradiance $=1$ ) for the HID light source, the wavelengths of maximal irradiance, respectively. Readings were made at 10-nm intervals.

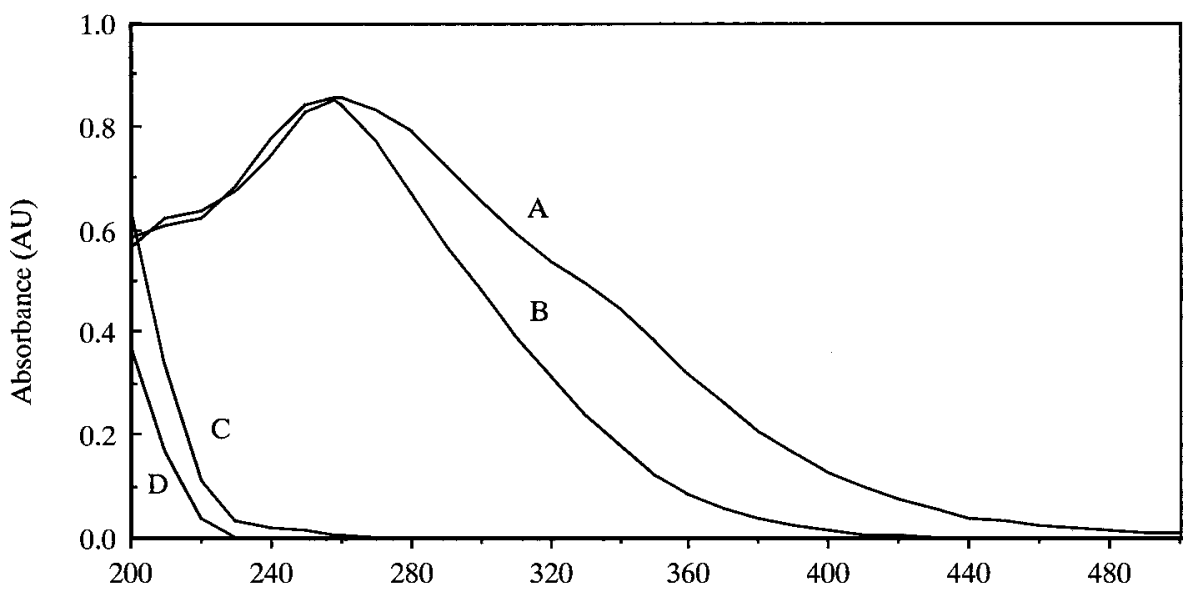

Wavelength (nm)

Fig. 2. Absorbance by $89.5 \mu \mathrm{mol} \cdot \mathrm{L}^{-1}$ solutions of FeDTPA [(A) nonirradiated and (C) irradiated (supernatant)] and FeEDTA [(B) nonirradiated and (D) irradiated (supernatant)]. Solutions were irradiated with $500 \mu \mathrm{mol} \cdot \mathrm{m}^{-2} \cdot \mathrm{s}^{-1}$ from a fluorescent plus incandescent light source. Soluble Fe concentration in the supernatant of the irradiated solutions was 0. Maximal absorbance by FeDTPA and FeEDTA was 260 and $258 \mathrm{~nm}$, respectively. 


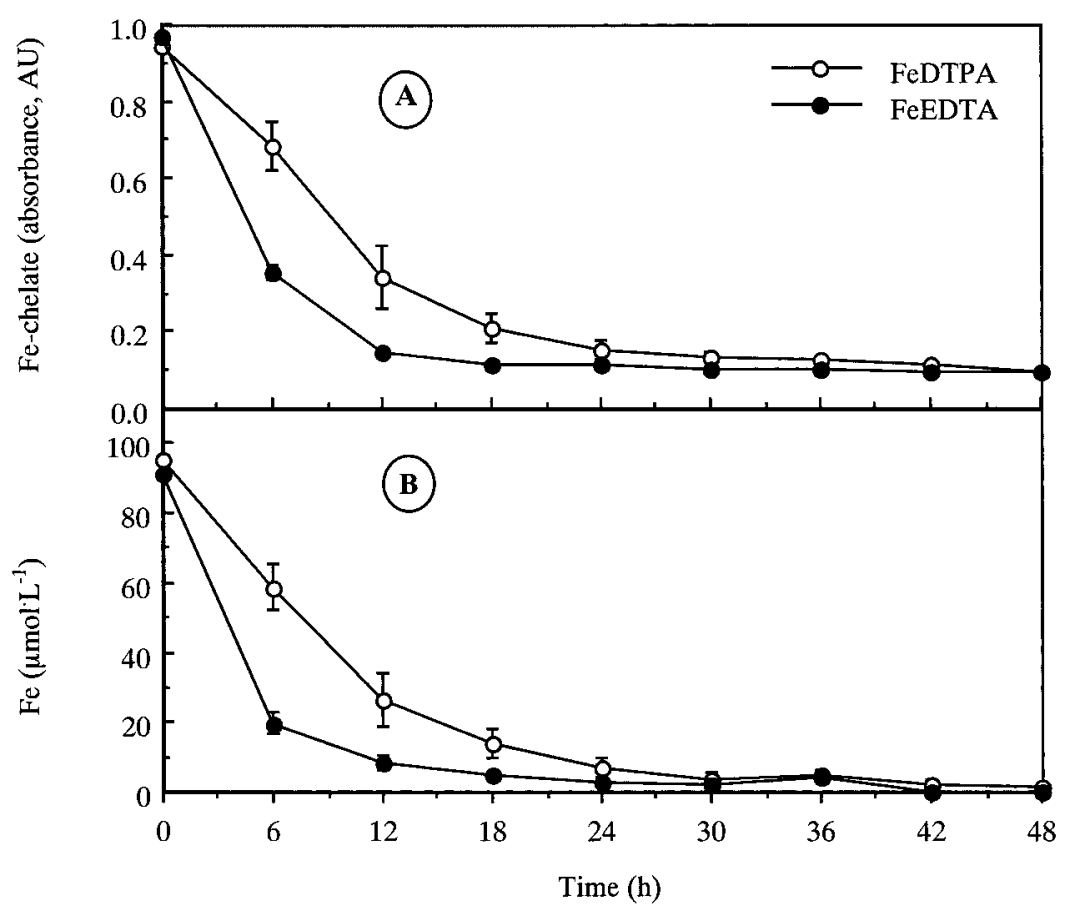

Fig. 3. (A) FeDTPA and FeEDTA determined spectrophotometrically at 260 or $258 \mathrm{~nm}$, respectively, and (B) soluble Fe determined by atomic absorption spectrophotometry for a lab-prepared nutrient solution. Nutrient solutions were $5 \times$ stocks $\left(14.28 \mathrm{mmol} \cdot \mathrm{L}^{-1} \mathrm{~N}, 17.9 \mu \mathrm{mol} \cdot \mathrm{L}^{-1} \mathrm{Fe}\right.$ is $\left.1 \times\right)$ irradiated at $30{ }^{\circ} \mathrm{C}$ with a HID light source providing $500 \mu \mathrm{mol} \cdot \mathrm{m}^{-2} \cdot \mathrm{s}^{-1}(330-800 \mathrm{~nm})$ measured at the surface of a 500-mL LDPE container. No absorbance was detected in solutions without Fe-chelate. Vertical bars indicate SE $(n=4)$. If none are shown, they fall within the dimensions of the plotting symbol.

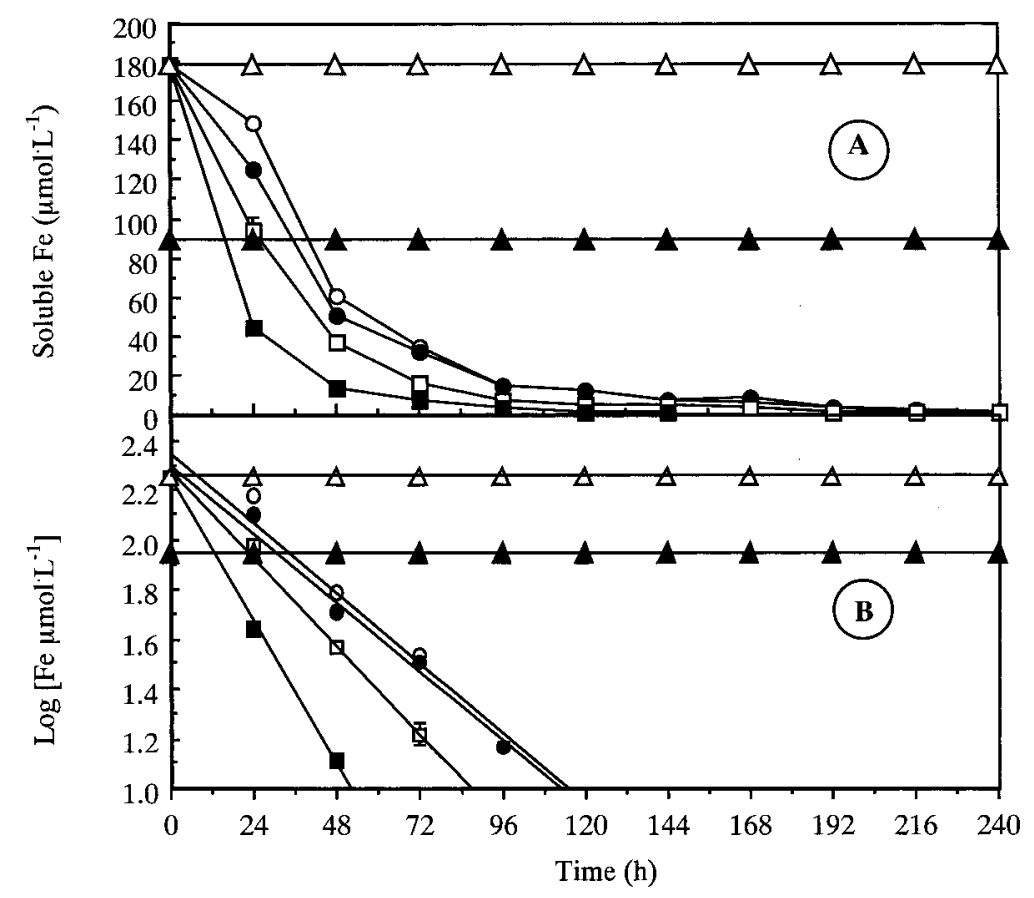

Fig. 4. (A) Loss of soluble Fe in linear plot vs. time and (B) linear regression profile of the logarithm of soluble Fe $\left(\mu \mathrm{mol} \cdot \mathrm{L}^{-1}\right)$ vs. time $(\mathrm{h})$ for $5 \times$ or $10 \times$ lab-prepared nutrient solutions containing FeDTPA or FeEDTA $\left(14.28 \mathrm{mmol} \cdot \mathrm{L}^{-1} \mathrm{~N}, 17.9 \mu \mathrm{mol} \cdot \mathrm{L}^{-1} \mathrm{Fe}=1 \times\right)$. Nutrient solutions $\left(20^{\circ} \mathrm{C}\right.$ or $\left.40^{\circ} \mathrm{C}\right)$ were irradiated with a fluorescent plus incandescent light source providing $250 \mu \mathrm{mol} \cdot \mathrm{m}^{-2} \cdot \mathrm{s}^{-1}$ or 500 $\mu \mathrm{mol} \cdot \mathrm{m}^{-2} \cdot \mathrm{s}^{-1}(330-800 \mathrm{~nm})$ measured at the outer surface of the container. Treatments were: 1$)$ FeEDTA, $10 \times, 20{ }^{\circ} \mathrm{C}, 250 \mu \mathrm{mol} \cdot \mathrm{m}^{-2} \cdot \mathrm{s}^{-1}(\mathrm{O})$; 2) FeDTPA, $10 \times, 20{ }^{\circ} \mathrm{C}, 250 \mu \mathrm{mol} \cdot \mathrm{m}^{-2} \cdot \mathrm{s}^{-1}$ (O); 3) same as 2) but wrapped in aluminum foil $(\triangle)$; 4) same as 2), but at $\left.40{ }^{\circ} \mathrm{C}(\square) ; 5\right)$ same as 2), but at 500 $\left.\mu \mathrm{mol} \cdot \mathrm{m}^{-2} \cdot \mathrm{s}^{-1}(\boldsymbol{\square}) ; 6\right)$ same as 5$)$, but $5 \times$ and under spectral filter Acrylic yellow-2208 (A). All containers were $1 \mathrm{~L}$ except for the $5 \times$ treatment, which was a 500 -mL container. Vertical bars indicate $\mathrm{SE}(n=3)$. If none are shown, they fall within the dimensions of the plotting symbol. tissue-culture agar; irradiation from fluorescent lamps degraded the FeEDTA, but this could be prevented using spectral filter Acrylic yellow2208 to remove the region of the spectrum in which the Fe-chelate maximally absorbed (Hangarter and Stasinopoulos, 1991).

Iron $(98 \%$ of total) and $\mathrm{Mn}(5 \%$ of total) were lost following irradiation of FeDTPA (Table 1). Analysis of the yellow-tan precipitate that formed upon irradiation indicated that it was primarily composed of $\mathrm{Fe}$, a small amount of Mn (Table 1), and trace amounts of $\mathrm{Zn}, \mathrm{P}, \mathrm{K}$, $\mathrm{Ca}$, and $\mathrm{Mg}$ (data not shown). The precipitate contained $85 \%$ of the soluble Fe lost (Table 1). No precipitate formed in irradiated nutrient solutions containing no FeDTPA (data not shown). These dataindicate that the photodegradation of nutrient solutions primarily affects only FeDTPA in solution and that the solubility of other nutrients is generally unaffected (remaining $\geq 95 \%$ soluble) by this photochemical event. Manganese in these studies was supplied as MnEDTA. The chelating-agent EDTA has a higher affinity for, and forms a more stable complex with, Fe than with $\mathrm{Mn}$ within a $\mathrm{pH}$ range of 4.0-6.3 (Laurie et al., 1991). Therefore, we speculate that $\mathrm{Fe}$ released from chelation with DTPA by photodegradation may replace $\mathrm{Mn}$ on the MnEDTA chelate complex, causing precipitation of $\mathrm{Mn}$ as an oxide and the photodegradation of the EDTA molecule.

The by-products of EDTA, and presumably DTPA, photodegradation are amine residues (Hamaker, 1956). Upon irradiating FeEDTA, carboxyl groups are lost, and the photostability of the amine residue by-product increases (i.e., photostability: ethylenediaminetetraacetic acid < ethylenediaminetriacetic acid < ethylenediaminediacetic acid) (Hamaker, 1956). These by-products are capable of chelating $\mathrm{Fe}$ (Hamaker, 1956) and may partially account for the residual levels of Fe-chelate remaining in the irradiated nutrient solutions (Fig. 3A). The residual levels of $\mathrm{Fe}$-chelate remaining in the irradiated nutrient solutions may also be due to $\mathrm{Mn}$ and $\mathrm{Cu}$ ions and/or chelates that can be a source of interference for the spectrophotometric detection of Fe-chelates (Hill-Cottingham, 1957).

The $\mathrm{pH}$ of the FeDTPA- or FeEDTA- containing nutrient solutions rose slightly when irradiated (Fig. 5). Amines are bases and their accumulation during photodegradation of the chelating agent may account for the rise in $\mathrm{pH}$ when such solutions are irradiated.

Effects of light intensity and temperature. Lab-prepared nutrient solutions lost $>90 \%$ of their soluble $\mathrm{Fe}$ during exposure to the light (fluorescent plus incandescent source) and temperature environments of $250 \mu \mathrm{mol} \cdot \mathrm{m}^{-2} \cdot \mathrm{s}^{-1}$ at $20{ }^{\circ} \mathrm{C}, 500 \mu \mathrm{mol} \cdot \mathrm{m}^{-2} \cdot \mathrm{s}^{-1}$ at $20{ }^{\circ} \mathrm{C}$, or 250 $\mu \mathrm{mol} \cdot \mathrm{m}^{-2} \cdot \mathrm{s}^{-1}$ at $40{ }^{\circ} \mathrm{C}$ (Fig. 4A). Plotting log [soluble $\mathrm{Fe}$ ] vs. time generated straight lines for all treatments $\left(r^{2} \geq 0.97\right)$, indicating that the reactions, as determined by the disappearance of soluble Fe, were first order (Fig. 4B, Table 2).

Linear regression analysis of the data in Fig. 4 indicated differences in rate constants (k) for both temperature and irradiation. At $20{ }^{\circ} \mathrm{C}$, doubling the irradiance from 250 to $500 \mu \mathrm{mol} \cdot \mathrm{m}^{-2} \cdot \mathrm{s}^{-1}(330-800 \mathrm{~nm})$ resulted in a 


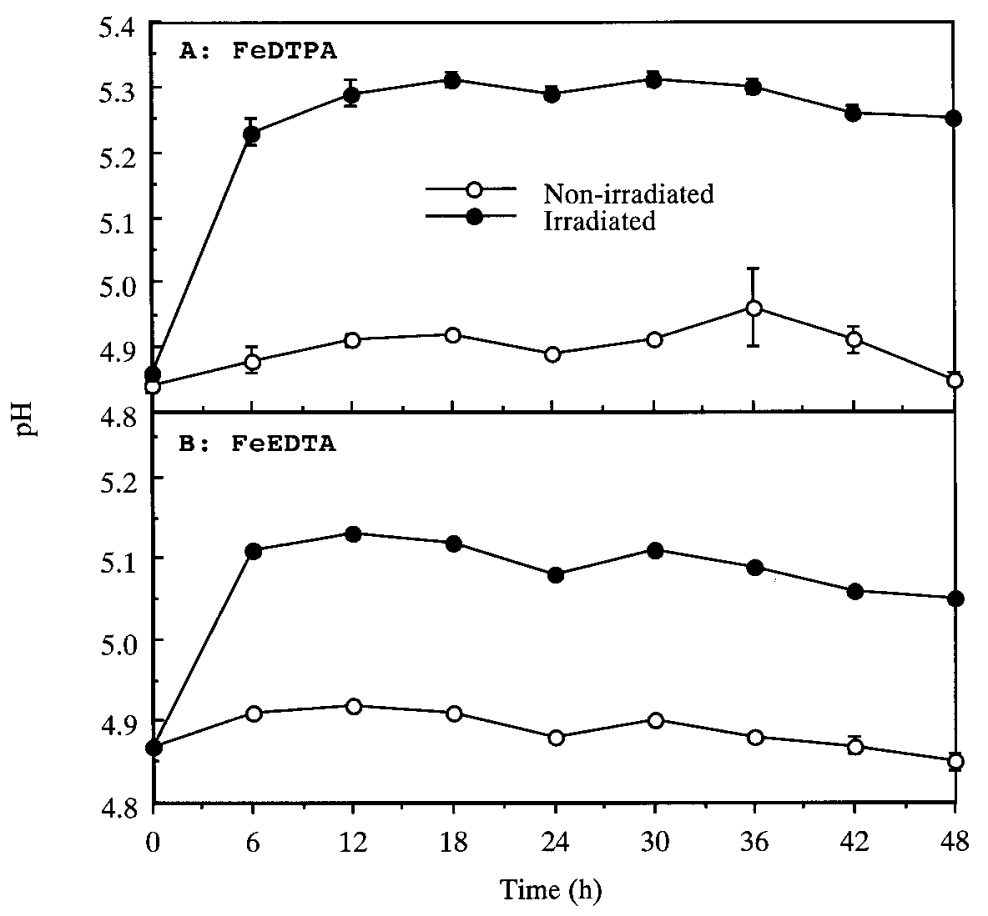

Fig. 5. $\mathrm{pH}$ of irradiated or nonirradiated lab-prepared nutrient solution vs. time of irradiation at $30{ }^{\circ} \mathrm{C}$. Solutions containing either (A) FeDTPA or (B) FeEDTA were prepared as $5 \times$ stocks $\left(14.28 \mathrm{mmol} \cdot \mathrm{L}^{-1} \mathrm{~N}\right.$, $\left.17.9 \mu \mathrm{mol} \cdot \mathrm{L}^{-1} \mathrm{Fe}=1 \times\right)$ and were irradiated with a HID light source providing $500 \mu \mathrm{mol} \cdot \mathrm{m}^{-2} \cdot \mathrm{s}^{-1}(330$ $800 \mathrm{~nm})$ measured at the surface of a 500-mL LDPE container. Vertical bars indicate SE $(n=4)$. If none are shown, they fall within the dimensions of the plotting symbol.

Table 1. Iron and Mn composition of supernatant and pellet fractions derived from nonirradiated (NIr) or irradiated (Ir) lab-prepared nutrient solutions. Nutrient solutions were irradiated as $4 \times$ stock solutions $\left(14.28 \mathrm{mmol} \cdot \mathrm{L}^{-1} \mathrm{~N}, 17.9 \mu \mathrm{mol} \cdot \mathrm{L}^{-1} \mathrm{FeDTPA}=1 \times\right)$ for $9 \mathrm{~d}$ with 500 $\mu \mathrm{mol} \cdot \mathrm{m}^{-2} \cdot \mathrm{s}^{-1}$ from a HID light source.

\begin{tabular}{|c|c|c|c|c|c|}
\hline \multirow[b]{2}{*}{ Element } & \multicolumn{2}{|c|}{ Supernatant $\left(\mu \mathrm{mol} \cdot \mathrm{L}^{-1}\right)$} & \multirow{2}{*}{$\begin{array}{c}\text { Loss due to } \\
\text { irradiation }(\%)\end{array}$} & \multirow{2}{*}{$\begin{array}{c}\text { Ir-Pellet } \\
\left(\mu \mathrm{mol} \cdot \mathrm{L}^{-1}\right)^{\mathrm{y}}\end{array}$} & \multirow{2}{*}{$\begin{array}{c}\text { Recovered } \\
(\%)\end{array}$} \\
\hline & $\mathrm{NIr}^{2}$ & Ir & & & \\
\hline $\mathrm{Fe}$ & 71.6 & 1.79 & 98 & 59.070 & 85.0 \\
\hline $\mathrm{Mn}$ & 36.4 & 34.58 & 5 & 0.016 & 0.9 \\
\hline $\mathrm{Fe}: \mathrm{Mn}$ ratio & $2: 1$ & $1: 19$ & --- & $3692: 1$ & --- \\
\hline
\end{tabular}

${ }^{2}$ No precipitate formed in the nonirradiated solution.

${ }^{y}$ The pellet derived from the irradiated solution was dissolved in $1 \mathrm{~N} \mathrm{HCl}$ prior to analysis, therefore, data are reported as concentrations.

Table 2. Linear regression (slope, $r^{2}$ ) and kinetic $(k)$ data describing the first order reaction of soluble $\mathrm{Fe}$ disappearance from solutions irradiated with a fluorescent plus incandescent light source for $10 \mathrm{~d}$ at the temperatures and irradiance levels indicated. Solution temperature was maintained by adjusting air temperature, and irradiance was varied by adjusting the lamp bank distance to containers within a controlled-environment growth chamber. Each solution contained $179 \mu \mathrm{mol} \cdot \mathrm{L}^{-1} \mathrm{FeDTPA}$ or FeEDTA (Fe source) incorporated into a $10 \times$ nutrient solution $\left(14.28 \mathrm{mmol} \cdot \mathrm{L}^{-1} \mathrm{~N}, 17.9 \mu \mathrm{mol} \cdot \mathrm{L}^{-1} \mathrm{Fe}\right.$ is $\left.1 \times\right)$. There was no loss in soluble Fe in nonirradiated treatments or irradiated treatments under spectral filter Acrylic yellow-2208 (wavelength cut off $454 \mathrm{~nm}$ ) at either solution temperature or irradiance.

\begin{tabular}{lcccccc}
\hline \hline Fe source & $\begin{array}{c}\text { Solution } \\
\text { temp. } \\
\left({ }^{\circ} \mathrm{C}\right)\end{array}$ & $\begin{array}{c}\text { Irradiance } \\
\left(\mu \mathrm{mol} \cdot \mathrm{m}^{-2} \cdot \mathrm{s}^{-1} \text { at }\right. \\
330-800 \mathrm{~nm})\end{array}$ & $\begin{array}{c}\text { Time to } \geq 90 \% \\
\text { sol. Fe loss }(\mathrm{h})\end{array}$ & $\begin{array}{c}\text { Slope }^{\mathrm{z}} \\
\left(\cdot 10^{-4} \cdot \mathrm{h}^{-1}\right)\end{array}$ & $r^{2 z}$ & $\begin{array}{c}\text { Rate constant } \\
k\left(\cdot 10^{-5} \cdot \mathrm{min}^{-1}\right)^{\mathrm{y}}\end{array}$ \\
\hline FeEDTA & 20 & 250 & $96 \mathrm{a}^{\mathrm{x}}$ & $-4.6 \mathrm{c}$ & 0.986 & $1.8 \mathrm{c}$ \\
FeDTPA & 20 & 250 & $96 \mathrm{a}$ & $-5.0 \mathrm{c}$ & 0.970 & $1.9 \mathrm{c}$ \\
& 20 & 500 & $48 \mathrm{c}$ & $-10.0 \mathrm{a}$ & 0.999 & $3.8 \mathrm{a}$ \\
& 40 & 250 & $72 \mathrm{~b}$ & $-6.3 \mathrm{~b}$ & 0.995 & $2.4 \mathrm{~b}$ \\
\hline
\end{tabular}

${ }^{\mathrm{z}}$ Calculated to the time point of $90 \% \mathrm{Fe}$ loss. Rate constant $(k)$ was calculated from raw data by linear regression analysis of the logarithm of soluble Fe vs. time (i.e., disappearance of substrate). ${ }^{y} k=-2.303 \cdot\left(\right.$ slope $\left.\cdot \mathrm{min}^{-1}\right)$.

${ }^{x}$ Means separation within columns by LSD at $P \leq 0.05 . n=3$. doubling of the rate constant $(k)$ of FeDTPA photodegradation (Table 2). At 250 $\mu \mathrm{mol} \cdot \mathrm{m}^{-2} \cdot \mathrm{s}^{-1}$ irradiance, a $20{ }^{\circ} \mathrm{C}$ increase in temperature from 20 to $40^{\circ} \mathrm{C}$ resulted in a $26 \%$ increase in the rate constant $(k)$ of FeDTPA photodegradation (Table 2). Most thermochemical reactions have a $Q_{10}$ of 2 to 3 (Petrucci and Wismer, 1993). The low $\mathrm{Q}_{10}$ confirms that the reaction is a photochemical event.

Conclusions. We have demonstrated that FeDTPA incorporated into lab-prepared nutrient solutions is vulnerable to photodegradation, resulting in selective Fe insolubility, but generally not affecting the solubility of other nutrients. The rate of FeDTPA photodegradation increased with temperature or irradiance, but irradiance had a far greater effect. Photodegradation of FeDTPA or FeEDTA resulted in a rise in solution $\mathrm{pH}$. FeDTPA absorbs in the blue and UV regions of the spectrum; removal of these wavelengths with a spectral filter prevented photodegradation. The consequences of using a photodegraded FeDTPA-containing nutrient solution on plant growth and physiology are presented in a second report (Albano and Miller, 2001).

\section{Literature Cited}

Albano, J.P. and W.B. Miller. 1996. Iron deficiency stress influences physiology of iron acquisition in marigold (Tagetes erecta L.). J. Amer. Soc. Hort. Sci. 121:438-441.

Albano, J.P. and W.B. Miller. 2001. Photodegradation of FeDTPA in nutrient solutions. II. Effects on root physiology and foliar $\mathrm{Fe}$ and Mn levels in marigold. HortScience 36:317-320.

Frisell, W.R., C.W. Chung, and C.G. Mackenzie. 1959. Catalysis of oxidation of nitrogen compounds by flavin coenzymes in the presence of light. J. Biol. Chem. 234:1297-1302.

Hamaker, J.W. 1956. Photodecomposition of ethylenediamine tetraacetic acid-ferric chelate. Symp. on the use of metal chelates in plant nutrition. Proc. Western Soc. Soil Sci. p. 64. (Abstr.)

Hangarter, R.P. and T.C. Stasinopoulos. 1991. Effect of Fe-catalyzed photooxidation of EDTA on root growth in plant culture media. Plant Physiol. 96:843-847.

Hill-Cottingham, D.G. 1957. A spectrophotometric method of analysis of chelate solutions and its application to the study of iron chelates in soils and plants. Soil Sci. 84:43-49.

Jackson, M.L. 1958. Soil chemical analysis. Prentice Hall, Englewood Cliffs, N.J.

Kolthoff, I.M., E.B. Sandell, E.J. Meehan, and S. Bruckenstein. 1969. Quantitative chemical analysis. Macmillan, London.

Laurie, S.H., N.P. Tancock, S.P. McGrath, and J.R. Sanders. 1991. Influence of complexation on the uptake by plants of iron, manganese, copper and zinc. I. Effect of EDTA in a multi-metal and computer simulation study. J. Expt. Bot. 42:509513.

Norvell, W.A. 1971. Equilibria of metal chelates in soil solution, p. 115-137. In: J.J. Mortvedt, P.M. Giordano, W.L. Lindsay, R.C. Dinauer, V.S. Clark, and P. Eith (eds.). Micronutrients in agriculture. Soil Sci. Soc. Amer., Madison, Wis.

Petrucci, R.H. and R.K. Wismer. 1983. General chemistry with qualitative analysis. Macmillian, New York.

Wallace, A., E. Frolich, and R.T. Mueller. 1967. Effect of solution $\mathrm{pH}$ on sunlight stability of FeEDDHA. Agron. J. 59:86 